\title{
Is the go/no-go lexical decision task an alternative to the yes/no lexical decision task?
}

\author{
MANUEL PEREA, EVA ROSA, and CONSOLACIÓN GÓMEZ \\ Universitat de València, València, Spain
}

\begin{abstract}
In the go/no-go lexical decision task (LDT), participants are instructed to respond as quickly as they can when a word is presented and not to respond if a nonword is presented. By minimizing part of the response selection process in the experimental task, the impact of response decision time on the obtained lexical decision time is probably reduced relative to the standard yes/no LDT (Gordon, 1983). Experiments 1 and 2 show that the go/no-go LDT is sensitive to the effects of word frequency and associative priming - the magnitude of these effects is similar with the two tasks. More important, the go/no-go LDT has a number of advantages with respect to the "standard" yes/no LDT: It offers faster response times, more accurate responding, and fewer processing demands than does the yes/no task. Accordingly, the go/no-go task appears to be an excellent alternative to the standard yes/no task.
\end{abstract}

The lexical decision task (LDT for short) has been the most widely used task in the study of visual word recognition. In the standard yes/no LDT, participants are to decide as rapidly and as accurately as possible whether a string of letters is a word or not by pressing either the word or the nonword key on a response box. However, in the usual experimental setup, after noting whether the letter string is a word or not, the participant must remember which response to make for the words and which response to make for the nonwords. Since this assignment is arbitrary, it may cause variability in the produced lexical decision times that is due to deciding what response to make, which is not relevant to the process of interest (see Pachella, 1974). In fact, participants often make errors in the LDT, not because they have misclassified the letter string, but because, once they have classified the letter string, they have executed the wrong response.

In order to avoid these problems, a go/no-go LDT has been proposed instead (see Gordon, 1983; Gordon \& Caramazza, 1982). In the go/no-go LDT, the participant is instructed to respond as quickly as he or she can when a word is presented but to withhold any response if the presented stimulus is a nonword. (Another form of the go/no-go LDT would be to respond to a nonword and withhold response to a word; see Measso \& Zaidel, 1990.) This makes

Parts of this research were reported at the 41st Annual Meeting of the Psychonomic Society, New Orleans, 2000. The first author was supported by a grant from the Secretaría de Estado de Educación y Universidades of Spain. The second and third authors were recipients of predoctoral grants from the Spanish Ministry of Science and Culture. We thank Steve Lupker, Ken Paap, Yasushi Hino, Gregory Ashby, and two anonymous reviewers for helpful and constructive criticism on earlier versions of this paper. Correspondence concerning this paper should be sent to M. Perea, Departament de Metodologia, Facultat de Psicologia, Av. Blasco Ibáñez, 21, 46010-València, Spain (e-mail: mperea@uv.es).

-Accepted by previous editorial team the comparison between tasks similar to the comparison between Donders's (1868/1969; see also Luce, 1986) Type B and Type $\mathrm{C}$ reaction time (RT) tasks. In the Type B reaction task (as in the yes/no LDT), the participant must make a distinct response to each of several possible stimuli, whereas in the Type $\mathrm{C}$ reaction task (as in the go/no-go LDT), a response is required to only one of several possible stimuli. Nonetheless, we must be assured that the go/no-go procedure applied to the LDT gives the same- or bettermeasures of the variables of interest and that this procedure does not fundamentally modify the processes of interest underlying the experimental task.

The processing in the two tasks would presumably involve selecting the appropriate lexical unit (lexical selection stage) and completing whatever decision-making processes are necessary to verify that it is the appropriate unit (response decision stage). The basic difference between making a correct word response in the two tasks seems to be the mental operations involved in the response selection stage. In the yes/no task, after deciding whether the letter string is a legitimate word, participants are required to choose one of two alternative responses (word or nonword). In the go/no-go task, the response selection process is apparently simpler, because nonwords do not require an overt response (Gibbs \& Van Orden, 1998; Gordon, 1983; Yelland, 1993). As a result, if a successful lexical selection is diagnostic of the letter string's being a word, and if we assume a discrete stage model of performance in which the subprocesses are identified as successive temporal stages, any lexical effects (e.g., word frequency, associative priming) should be approximately the same size in the two tasks (i.e., additive-factor method; Sternberg, 1969). (We discuss an alternative account in the General Discussion section.)

The main goal of this study is to evaluate the possibility of using the go/no-go version of the lexical decision task as a replacement for the standard yes/no version. Although the lexical decision task has had a controversial history 
(see, e.g., Balota \& Chumbley, 1984, 1990; Grainger \& Jacobs, 1996; Hino \& Lupker, 1996, 1998; Monsell, Doyle, \& Haggard, 1989; Paap, McDonald, Schvaneveldt, \& Noel, 1987; Pollatsek, Perea, \& Binder, 1999), it is likely that researchers will continue to use it, since competing tasks - such as the pronunciation task-have their own problems (see, e.g., Forster \& Shen, 1996; Paap et al., 1987). Thus, it seems reasonable to examine any modifications in the procedure of the lexical decision that can make it more sensitive and valid in the scientific enterprise. In order to compare the two techniques, we will focus on four important criteria. ${ }^{1}$

1. The number of errors. This is not a trivial issue, since firm conclusions about the locus of the effect of a manipulation must be restricted to cases in which error rates are very low (McClelland, 1979). It is difficult to construe the reduced errors to word stimuli as anything but positive. In this light, several studies have consistently found that participants commit substantially fewer errors in the responses to words in the go/no-go task than in the yes/no task (Gibbs \& Van Orden, 1998; Gordon \& Caramazza, 1982; Hino \& Lupker, 1998, 2000; Perea, Fernández, \& Carreiras, 1998). ${ }^{2}$ In addition, the data concerning false positive errors (i.e., nonword error rates: word responses to nonword stimuli) needs to be taken into account, since this is critical for an accurate evaluation of performance in go/no-go tasks, as compared with binary decision tasks (i.e., it may alter the speed with which one responds to the word stimuli).

2. The speed of the RT. Undoubtedly, it is desirable to use a word identification task that minimizes time-consuming decisional processes that are unnecessary to recognize a given word, so that RTs will be closer to the total duration of eye fixations on a word when it is read in isolationaround 350-450 msec, (see, e.g., Grainger, O'Regan, Jacobs, \& Seguí, 1989). In this context, RTs are generally faster with the go/no-go task than with the yes/no task (e.g., Chiarello, Nuding, \& Pollock 1988; Gordon \& Caramazza, 1982; Measso \& Zaidel, 1990; Perea et al., 1998; but see Gibbs \& Van Orden, 1998; Hino \& Lupker, 1998, 2000). However, the fact that the participants in most of the above-cited experiments were not randomly assigned to each level of task (except in the experiments by Chiarello et al., 1988, and Measso \& Zaidel, 1990) makes it difficult to compare the main effect of task.

3. The variability in the data. There is little doubt that reduced variability (noise) is a desirable property in the data from any word identification task. Gordon $(1983,1985)$ indicated that by minimizing part of the response selection process in the experimental task, the impact of response decision time on the obtained lexical decision time in the go/no-go task would be reduced (relative to the standard yes/no task), thereby reducing subsequent variability. However, Gordon (1983, 1985; Gordon \& Caramazza, 1982) did not report data that can be used to assess this claim. In fact, recent published studies have generally found higher values - if anything - for mean square errors $\left(M S_{\mathrm{e}} \mathrm{s}\right)$ in the go/no-go task than in the yes/no task (Hino \& Lupker, 1998, 2000; but see Measso \& Zaidel, 1990).

4. Task demands. The simpler the task is, the less timeconsuming decisional, task-specific processes will be necessary to make a correct word response. In this light, the go/no-go task appears to be simpler to perform than the yes/no task (see above). For instance, Yelland (1993) indicated that the go/no-go LDT (but not the yes/no LDT) can easily be applied to experiments with special populations (e.g., children; see also Davis, Castles, \& Iakovidis, 1998).

In Experiment 1, we reexamine the word frequency effect with the two techniques. The two techniques produced similar RT versus word frequency functions in the Gordon and Caramazza (1982) study. In an on-going project, one of us also found a similar word frequency advantage in the yes/no LDT and in the go/no-go LDT (74 vs. $63 \mathrm{msec}$, respectively; Perea et al., 1998). However, Hino and Lupker (1998; see also Hino \& Lupker, 2000) found larger word frequency effects with the go/no-go LDT than with the yes/no task (see below), which casts doubt on the conclusion that the two factors have additive effects on RT. In Experiment 2, we examine the presence of an automatic associative priming effect with the two techniques. More important, Experiment 2 analyzes whether the latencies in a second block of trials (with a yes/no task or a go/no-go task) are modulated by the task used in the first block (go/no-go or yes/no task), that is, task is manipulated both between subjects and within subjects.

\section{The Word Frequency Effect in the Yes/No and the Go/No-Go Lexical Decision Task}

Although most models of visual word recognition assume that the time taken to access the lexical entry of a word in the mental lexicon is mainly governed by the frequency of occurrence of the word (e.g., search model, Forster, 1976; resonance model, Gordon, 1983; multiple read-out model, Grainger \& Jacobs, 1996; interactive activation model, McClelland \& Rumelhart, 1981; activation-verification model, Paap, Newsome, McDonald, \& Schvaneveldt, 1982), other authors (e.g., Balota \& Chumbley, 1984, 1990) argue that word frequency also impacts the response decision stage. Nonetheless, if it is true that the difference between the two tasks is in the response selection stage (rather than in the lexical selection or the response decision stage), we can still conclude that the yes/no LDT and the go/no-go LDT should show a word frequency effect of similar size (see Gordon \& Caramazza, 1982, and Perea et al., 1998, for a demonstration of the effect).

However, Hino and Lupker (1998) found a much larger word frequency effect in the go/no-go LDT $(163 \mathrm{msec})$ than in the yes/no LDT (107.5 msec). Given that the word frequency effect in the yes/no LDT might be inflated by the response decision stage (e.g., the word frequency effect is larger in the yes/no LDT than in the standard naming task or in a reading task; see Perea \& Pollatsek, 1998; Schilling, Rayner, \& Chumbley, 1998), it does not seem reasonable to argue that lexical decisions with the stan- 
dard yes/no procedure would underestimate the word frequency effect. Rather, the larger word frequency effect in the go/no-go LDT would call into question the role of word frequency in the lexical selection process (see Hino \& Lupker, 1998, for a discussion of this issue).

Hino and Lupker (1998) proposed an ingenious explanation for the different magnitude of the word frequency effect on the basis of the different demands of the two tasks: In the yes/no LDT, there is pressure to make a rapid response to all stimuli (words and nonwords). When an unfamiliar low-frequency word is encountered, participants might make the wrong answer, and these trials would end up counting as errors and not contributing to the mean latency for low-frequency words. In contrast, in the go/no-go LDT, nonwords do not require a response. Thus, when an unfamiliar word is encountered, a trialterminating negative response would not be made, and lexical processing would continue. In this case, the participant may make a slow response (assuming that the word is in the individual's vocabulary). Consistent with this interpretation, Hino and Lupker (1998) found that error rate decreased for low-frequency words with the go/no-go LDT (19.3\% vs. $8.4 \%$ ), whereas mean latency for lowfrequency words increased with the go/no-go LDT ( 684.5 vs. $656 \mathrm{msec}$ ). In contrast, mean latency for high-frequency words decreased in the go/no-go LDT (522 vs. $548 \mathrm{msec}$ ), which is reasonable given that the go/no-go LDT seems to be simpler than the yes/no LDT. However, Hino and Lupker (1998) did not provide any additional statistical analyses in support of their explanation. Mean lexical decision time would be of limited use as a statistic in this case, because the main interest is the shape of the response time distribution (see, e.g., Balota \& Spieler, 1999).

More recently, Hino and Lupker (2000) found a somewhat larger word frequency effect in the go/no-go LDT $(120.5 \mathrm{msec})$ than in the yes/no LDT $(96 \mathrm{msec}$; a difference less than half in size of that in their 1998 paper). The reliability of the interaction between task and word frequency was not tested, however. They concluded that "the task-specific nature of the frequency effects in the standard and go/no-go LDTs suggests that these results are more consistent with a task-specific account" (Hino \& Lupker, 2000,pp. 179-180). We would like to note that RTs in the go/no-go LDT were much greater than those in the yes/no LDT, not only for low-frequency words (715 vs. $635 \mathrm{msec}$, respectively), but also for high-frequency words (595 vs. $539 \mathrm{msec}$, respectively). This finding seems rather surprising, since the go/no-go LDT is presumably simpler than the yes/no LDT. It is likely that this difference was caused because the participants were not randomly assigned to each level of task (the two tasks were run over a year apart; Lupker, personal communication, January 20,2000 ), and thereby it may be misleading to compare the effect of task under these circumstances. In fairness to Hino and Lupker, we must note that the comparison between these two tasks was not the main focus of any of their two papers. Finally, it may be of interest to note that the nonword error rate (i.e., word responses to nonwords) was higher in the yes/no task than in the go/nogo task in the Hino and Lupker experiments $(13.0 \%$ vs. $8.7 \%$ in the 1998 experiment and $11.7 \%$ vs. $6.5 \%$ in the 2000 experiment), which suggests that the participants could have used different strategies - for example, a word bias in the yes/no task -in the two tasks (the overall word error rates for the yes/no and the go/no-go tasks were, respectively, $11.6 \%$ vs. $4.9 \%$ in the 1998 experiment and $6.7 \%$ vs. $4.1 \%$ in the 2000 experiment).

Given the theoretical implications of the Hino and Lupker results with respect to the role of word frequency in the lexical selection process, it is of theoretical relevance to establish why it is enhanced in at least some implementations of the go/no-go task. We must bear in mind that Gordon and Caramazza (1982) found a similar RT versus word frequency function with the two techniques (see also Perea et al., 1998). One basic difference between the Hino and Lupker (1998) study and the other two studies would be the range of word frequency: The low-frequency words in the Hino and Lupker (1998) study had a lower frequency of occurrence than did those employed by Gordon and Caramazza and Perea et al. Interestingly, in the Hino and Lupker (2000) paper, the low-frequency words were higher in frequency than those in their 1998 paper, and the interaction between word frequency and task was much weaker; it was not tested, however. Perhaps the effects found by Hino and Lupker (1998) are restricted to unfamiliar, very low frequency items. In order to examine this possibility, besides the high-frequency condition, we selected two groups of low-frequency words in Experiment 1: low-frequency words and very low frequency words (similar in frequency to the low-frequency words in the Hino \& Lupker, 1998, study). According to the Hino and Lupker (1998) analysis, the more straightforward outcome would be to observe additivity when high-frequency words are paired with low-frequency words, and an interaction when they are paired with the very low frequency words.

\section{EXPERIMENT 1 Word Frequency Effect}

\section{Method}

Participants. Forty-eight psychology students from the University of València took part in the experiment for course credit. All of them had either normal or corrected-to-normal vision and were native speakers of Spanish.

Materials. One hundred and twenty Spanish words were collected on the basis of the word frequency norms for Spanish (Alameda \& Cuetos, 1995). Forty of those words were of high frequency, 40 of low frequency, and 40 of very low frequency. Frequency counts for high-frequency words were greater than 125 per two million (mean, 348; range, 140-998), frequency counts for the low-frequency words were greater than 15 and less than 25 (mean, 20.5; range, 17-24), and frequency counts for the very low frequency words were less than 4 (mean, 2.4; range, 2-3). The target words were all 6 letters long. The 120 target nonwords were 80 stimuli constructed by changing an interior letter from a 6-letter Spanish word other than one from the experimental set (e.g., logeca; the word 
would be lógica, the Spanish for logic) and 40 stimuli constructed by transposing two interior letters from a 6-letter Spanish word other than one from the experimental set (e.g., tineda; the word would be tienda, the Spanish for shop).

Design. Task type (go/no-go LDT, yes/no LDT) was varied between participants (24 participants were randomly assigned at each level of task type), whereas word frequency (high frequency, low frequency, and very low frequency) was varied within participants. Each participant was given a total of 240 experimental trials: 120 word trials and 120 nonword trials.

Procedure. The participants were tested in groups of $4-8$ in a quiet room. Presentation of the stimuli and recording of RTs were controlled by Apple Macintosh Classic II microcomputers. The routines for controlling stimulus presentation and RT collection were obtained from Lane and Ashby (1987) and from Westall, Perkey, and Chute (1986), respectively. On each trial, the sequence " $><$ " was presented for $200 \mathrm{msec}$ on the center of the screen. After a 50-msec blank, a lowercase letter string was presented. The stimulus remained on the computer screen until the participant responded or until $2 \mathrm{sec}$ had elapsed (similar to the experiments of Gordon, 1983, and Hino \& Lupker, 1998, 2000). In the go/no-go task, the participants were instructed to press the mouse with their dominant hand if the letter string was a legitimate Spanish word. In the yes/no task, the participants were instructed to press one of two buttons on the keyboard to indicate whether the letter string was a Spanish word or not. The participants used their dominant hand to make the word response. In both tasks, this decision was to be made as rapidly and as accurately as possible. The intertrial interval was set to $400 \mathrm{msec}$. Each participant received a different random order of stimuli. Each participant received a total of 24 practice trials prior to the experimental phase. The session lasted approximately $15 \mathrm{~min}$.

\section{Results}

Lexical decision latencies less than $250 \mathrm{msec}$ or greater than $1,500 \mathrm{msec}$ were excluded from the latency analyses (less than $0.4 \%$ ). Mean lexical decision latencies for correct responses and mean error rates were calculated across individuals and across items. Participant and item analyses of variance (ANOVAs) based on the participants' and items' response latencies and error rates were conducted based on a 3 (word frequency, high, low, very low) $\times 2$ (task type, go/no-go LDT vs. yes/no LDT) design. The .05 level of significance was adopted throughout. The mean RTs and percentage error from the participant analysis are presented in Table 1.

Not surprisingly, in the analyses of response latencies, the main effect of word frequency was significant, $\left[F_{1}(2,92)=\right.$ $\left.329.69, M S_{\mathrm{e}}=579.5 ; F_{2}(2,117)=88.26, M S_{\mathrm{e}}=3,797.6\right]$ : High-frequency words were responded to faster than low-frequency words $\left[F_{1}(1,46)=218.78, M S_{\mathrm{e}}=345.8\right.$;
$\left.F_{2}(1,117)=33.36, M S_{\mathrm{e}}=3,797.6\right]$, and low-frequency words were responded to faster than very low frequency words $\left[F_{1}(1,46)=205.34, M S_{\mathrm{e}}=569.3 ; F_{2}(1,117)=55.86, M S_{\mathrm{e}}=\right.$ $3,797.6]$. The main effect of task type was also significant $\left[F_{1}(1,46)=6.73, M S_{\mathrm{e}}=23,420.9 ; F_{2}(1,117)=345.28\right.$, $\left.M S_{\mathrm{e}}=790.97\right]:$ The participants were faster with the go/no-go LDT than with the yes/no LDT. More important, the interaction between task type and word frequency was not significant $\left[F_{1}(2,92)=0.48, M S_{\mathrm{e}}=579.5 ; F_{2}(2,117)=\right.$ $\left.0.479, M S_{\mathrm{e}}=790.97\right]$. The magnitude of the word frequency effect was similar in the two tasks. Furthermore, the correlation between lexical decision time across items in the two tasks was quite high $(r=.85)$, which indicates that the two tasks bear a high degree of similarity. Finally, we should note that if we analyze separately the two tasks, error variance was a bit higher with the go/no-go task than with the yes/no task (the differences were not significant, however): The $M S_{\mathrm{e}}$ s for the word frequency effect were 370.91 versus $320.71\left(F_{1}\right)$ and $2,475.33$ versus $2,113.23$ $\left(F_{2}\right)$, respectively.

In the analyses of word error rates, the main effect of word frequency was also significant $\left[F_{1}(2,92)=48.37\right.$, $\left.M S_{\mathrm{e}}=7.87 ; F_{2}(2,117)=14.21, M S_{\mathrm{e}}=44.63\right]$. In addition, the participants made fewer errors with the go/no-go LDT than with the yes/no LDT $\left[F_{1}(1,46)=39.74, M S_{\mathrm{e}}=15.7\right.$; $\left.F_{2}(1,117)=51.08, M S_{\mathrm{e}}=19.5, p<.001\right]$. The interaction between task type and word frequency was significant $\left[F_{1}(1,102)=375.31, M S_{\mathrm{e}}=684 ; F_{2}(1,162)=20.56, M S_{\mathrm{e}}=\right.$ 19.5], which reflected the existence of a floor effect with the go/no-go LDT (see Table 1).

\section{Discussion}

The present experiment has shown that the RTs were faster and more accurate with the go/no-go task than with the yes/no task. Furthermore, the word frequency advantage in the go/no-go LDT was the same magnitude as that in the yes/no LDT: Lexical decision times were about $67 \mathrm{msec}$ faster in the go/no-go LDT across the three word frequency conditions. This result is consistent with some findings (Gordon \& Caramazza, 1982; Perea et al., 1998) but contradicts other recent results (Hino \& Lupker, 1998, 2000). It is important to stress that this word frequency advantage in the go/no-go task was not accompanied by a larger number of false positive responses [the percentage of false positive errors was similar in the two tasks; $F(1,46)<1]$. Finally, we should note that contrary to Gor-

Table 1

Mean Response Times (RTs, in Milliseconds) and Percentages of Error (PE) for the Word Targets With the Go/No-Go Lexical Decision Task (LDT) and with the Yes/No LDT

\begin{tabular}{|c|c|c|c|c|c|c|}
\hline \multirow[b]{3}{*}{ LDT } & \multicolumn{6}{|c|}{ Word Frequency } \\
\hline & \multicolumn{2}{|c|}{ High } & \multicolumn{2}{|c|}{ Low } & \multicolumn{2}{|c|}{ Very Low } \\
\hline & $M$ & $\mathrm{PE}$ & $M$ & $\mathrm{PE}$ & $M$ & $\mathrm{PE}$ \\
\hline Go/no-go & 544 & 0.0 & 598 & 0.4 & 673 & 2.4 \\
\hline Yes/no & 611 & 1.7 & 669 & 3.6 & 734 & 10.0 \\
\hline Difference & 67 & 1.7 & 71 & 3.2 & 61 & 7.6 \\
\hline
\end{tabular}

Note-Mean RTs for nonwords in the yes/no LDT were $779 \mathrm{msec}$. Mean error rates for nonwords were $5.8 \%$ and $5.4 \%$ for the go/no-go LDT and the yes/no LDT, respectively. 
don's (1983) claim, error variance was not lower with the go/no-go task than with the yes/no task.

It seems necessary to explain why Hino and Lupker (1998) found a stronger word frequency effect in the go/nogo task than in the yes/no task. As we said in the introduction, Hino and Lupker (1998) indicated that when an unfamiliar low-frequency word is encountered, participants might make the wrong answer in the yes/no task, and those trials would end up counting as errors and not contributing to the mean latency for that condition. In contrast, in the go/no-go LDT, nonwords do not require a response and the participant could eventually realize that the unfamiliar item is a word, producing a slow response and, thereby, a larger word frequency effect. Obviously, an analysis based on the mean RTs per condition is not the best way to test this hypothesis. Instead, we proceeded to compare the shapes of the group RT distributions by using the procedure described extensively by Ratcliff (1979). ${ }^{3}$ If participants make a higher number of slow responses to the very low frequency words in the go/no-go LDT than in the yes/no LDT, the right tail of the RT distribution should be longer for the go/no-go LDT. However, the Vincent histograms with 5\% quantiles based on all the correct RTs show that the RT distribution for the go/no-go task does not have a longer tail than the RT distribution for the yes/no task (if anything, the distribution is a bit more skewed in the yes/no task; see Figure 1). Of course, it could be argued that this analysis would be more informative when conducted on the Hino and Lupker (1998) data, since our data showed additive effects of word frequency and task. Nevertheless, we believe that it is important to show that the RT distributionsin the two tasks have a similar shape.

But there is another way to test Hino and Lupker's (1998) interpretation. If the Hino and Lupker (1998) account is correct, words with a high percentage of errors (i.e., the "difficult" words) should show faster lexical decision times in the yes/no LDT than in the go/no-go LDT. Only 4 out of the 40 very low frequency words in our experiment showed a faster mean lexical decision time in the yes/no LDT than in the go/no-go LDT. Consistent with Hino and Lupker's (1998) interpretation, two of these words (dehesa and billón; the Spanish for pasture and billion, respectively) showed, by far, the highest error rates in the experiment ( $25 \%$ of the errors each in the go/no-go LDT and $41.7 \%$ of the errors each in the yes/no LDT). ${ }^{4}$ As a result, it could be argued that the $10 \%$ error rate observed with the very low frequency words in the yes/no LDT was too small to trigger the Hino and Lupker (1998) pattern. As we indicated earlier, the word frequency $\times$ task interaction was relatively weak in the Hino and Lupker (2000) paper, in which the low-frequency words were higher in frequency than those in their 1998 paper. ${ }^{5}$ Thus, part of the word frequency effect reported by Hino and Lupker (1998)
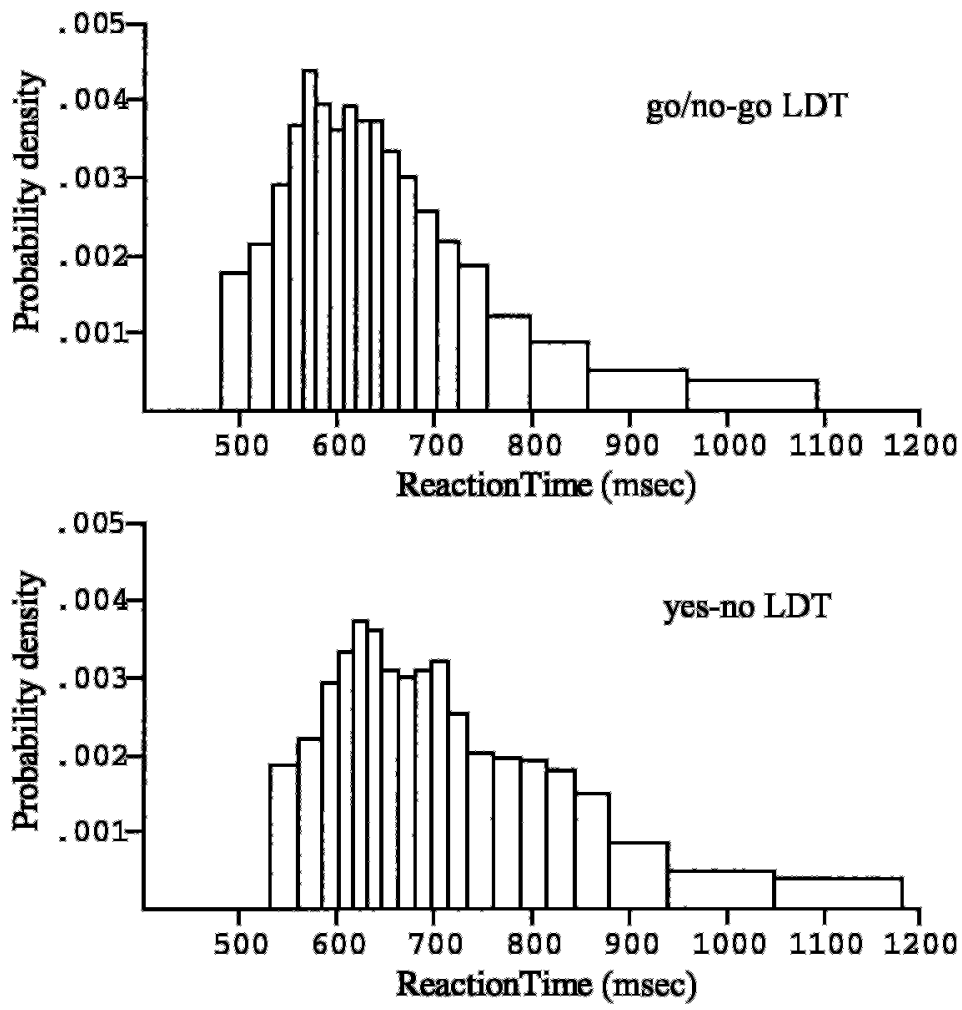

Figure 1. Group reaction time distributions for the very low frequency words in the go/no-go lexical decision task (LDT) and the yes/no LDT. 
Table 2

Summary of Word Frequency Studies (Mean Response Times and Percentages of Error) That Have Used Both the Go/No-Go Task and the Yes/No Task

\begin{tabular}{|c|c|c|c|c|c|c|c|c|c|}
\hline \multirow[b]{3}{*}{ Task } & \multicolumn{6}{|c|}{ Word Frequency } & \multirow[b]{3}{*}{ WF Effect } & \multirow{2}{*}{\multicolumn{2}{|c|}{ Nonword }} \\
\hline & \multicolumn{2}{|c|}{ High } & \multicolumn{2}{|c|}{ Low } & \multicolumn{2}{|c|}{ Very Low } & & & \\
\hline & $M$ & $\mathrm{PE}$ & $M$ & $\mathrm{PE}$ & $M$ & $\mathrm{PE}$ & & $M$ & $\mathrm{PE}$ \\
\hline \multicolumn{10}{|l|}{ Experiment 1} \\
\hline Go/no-go & 544 & 0.0 & 598 & 0.4 & 673 & 2.4 & $129 / 54$ & - & 5.8 \\
\hline Yes/no & 611 & 1.7 & 669 & 3.6 & 734 & 10.0 & $123 / 68$ & 779 & 5.4 \\
\hline \multicolumn{10}{|c|}{ Perea, Fernández, and Carreiras (1998) } \\
\hline Go/no-go & 544 & 0.0 & 618 & 0.5 & - & - & 74 & - & 3.4 \\
\hline Yes/no & 591 & 1.3 & 654 & 6.1 & - & - & 63 & 736 & 3.5 \\
\hline \multicolumn{10}{|c|}{ Hino and Lupker (1998) } \\
\hline Go/no-go & 522 & 1.4 & - & - & 685 & 8.4 & 163 & - & 8.7 \\
\hline Yes/no & 548 & 4.0 & - & - & 656 & 19.3 & 108 & 724 & 13.0 \\
\hline \multicolumn{10}{|c|}{ Hino and Lupker (2000) } \\
\hline Go/no-go & 594 & 1.0 & 715 & 7.2 & - & - & 121 & - & 6.5 \\
\hline Yes/no & 539 & 2.6 & 635 & 10.9 & - & - & 96 & 719 & 11.7 \\
\hline
\end{tabular}

Note-WF effect refers to the difference between the low-frequency (LF) words (and/or very low frequency words) and the high-frequency (HF) words.

in the go/no-go LDT could be attributed to participants' not knowing for sure the meaning of a particular word, rather than to the frequency of occurrence of that word.

Finally, it might be argued that the interaction between word frequency and task in the Hino and Lupker (1998) paper was caused by different participants' strategies in the experiments. ${ }^{6}$ We must bear in mind that the participants in our experiment made fewer errors-for both word and nonword stimuli (see Table 2) - than did those in the Hino and Lupker (1998) experiments, which may be taken to suggest that stimulus processing was somehow deeper in our experiment. (In addition, it seems that there was a word bias with the yes/no task, relative to the go/no-go task, in the Hino and Lupker, 1998, experiments.) If lexical decisions are based on deep processing of the stimuli, analytic processing would be made before making lexical decisions in both the yes/no LDT and the go/no-go LDT, and thereby a similar word frequency effect would be expected in the two tasks. However, if lexical decisions are based on shallow processing of the stimuli, the time pressure to make a rapid response in the yes/no LDT may provoke relatively fast lexical decision times to unfamiliar words (with the cost of a relatively high proportion of errors). In contrast, there is no time pressure for nonwords in the go/no-go LDT, which may provoke the presence of long lexical decision times for unfamiliar words and, thereby, a stronger frequency effect for the go/no-go task.

In sum, different participants' strategies-or the presence of unfamiliar low-frequency words-might provoke the presence of an interaction between word frequency and task, such as that found by Hino and Lupker $(1998,2000)$. What is more, one can take a very different perspective and imagine what would occur if participants were told that $10 \%$ was not an acceptable word error rate and, instead, they were asked to be as accurate in the yes/no task as they are in the go/no-go task $(2.4 \%) .^{7}$ The only cell in which participants need to trade speed for more accuracy is the very low frequency in the yes/no task. If they could do it, the mean RT of 734 msec would go higher, and again we would have a task $\times$ word frequency interaction, but in the opposite direction from that reported by Hino and Lupker $(1998,2000)$. (We will discuss this issue in the General Discussion section.)

\section{EXPERIMENT 2 Associative Priming Experiment}

It is well documented that a word (e.g., the target, CHAIR) is responded to faster when it is preceded by an associatively related word (the prime, table) than when it is preceded by an unrelated word: This is the associative priming effect (see Neely, 1991, for a review). In the classical spreading activation account, activation spreads along a lexical/semantic network, so that the prime word automatically preactivates associatively/semantically related words (Collins \& Loftus, 1975). Thus, the identification time of the subsequently preactivated words is sped up. As we said earlier, if a successful lexical selection is diagnostic of the letter string's being a word, the associative priming should be approximately the same size in the two techniques. Even assuming that additional decisional and response processing occurs after lexical access has already occurred, but before the overt lexical decision has been executed (e.g., semantic-checking processes; see de Groot, 1984; Neely, 1991), it is difficult to see how these processes can affect differentially the word decisions in the go/no-go LDT and the yes/no LDT.

To our knowledge, no previous associative priming experiments have compared the two techniques. ${ }^{8}$ In order to obtain strategy-free automatic activation, we used a stimulus onset asynchrony (SOA) between the prime and the target of $100 \mathrm{msec}$. The choice of $100 \mathrm{msec}$ as SOA was to make sure that the associative priming effect would be sizable (e.g., McNamara \& Altarriba, 1988, pointed out that automatic activation reaches asymptote in about $100 \mathrm{msec}$ ). One important feature of this experiment is that task 
(go/no-go LDT, yes/no LDT) was manipulated not only between subjects, but also within subjects. Specifically, half of the participants performed the go/no-go task in the first block and the yes/no task in the second block, whereas the other half performed the yes/no task in the first block and the go/no-go task in the second block. By doing this, we avoid the potential interpretive difficulties that may arise when comparing results across two different sets of participants.

\section{Method}

Participants. A total of 56 students from introductory psychology courses at the University of València took part in the experiment in exchange for course credit. All of them had either normal or corrected-to-normal vision and were native speakers of Spanish. None of them had participated in the previous experiment.

Materials. One hundred related pairs were selected from the freeproduction norms in Spanish supplied by Algarabel, Sanmartín, García, and Espert (1986). In all cases, the prime was the most frequent associate of the target (e.g., julio-AGOSTO; July-August). The mean associative strength was 35\% (range, 17\%-72\%). Unrelated primes were also created for each target. Unrelated and related primes were matched on number of letters and word frequency. The mean length in letters for the word-word pairs was 5.0 (range, 4-7) for the primes and 5.4 (range, 3-12) for the targets. One hundred word-nonword pairs were also created for the purposes of the lexical decision task. Nonwords were orthographically legal and had been constructed by replacing a letter of a Spanish word other than one of the experimental set.

Two sets of stimuli were created (Set A and Set B). Fifty word-word pairs were randomly assigned to Set A, whereas the other 50 wordword pairs were assigned to Set B. In each set, two stimulus lists were created for each set by matching each of those targets with either its associated prime or an unrelated prime. Word-word pairs were rotated across the priming condition across two groups of participants (in each block) so that no participant was presented any single prime or target word more than once but every participant received both priming conditions in each block. Specifically, the participants were randomly assigned to one of the following four sequences: Set A-List 1 Set B-List 2; Set A-List 2 Set B-List 1; Set B-List 1 Set A-List 2; Set B-List 2 Set A-List 1. With respect to the word-nonword trials, 50 pairs were randomly assigned to the first block, whereas the other 50 pairs were assigned to the second block.

Design. Task (go/no-go LDT, yes/no LDT) and prime-target relatedness (related, unrelated) were varied within participants.
Twenty-eight participants performed the go/no-go task in the first block and the yes/no task in the second block, whereas the other 28 participants performed the yes/no task in the first block and the go/no-go task in the second block. Each participant was given a total of 100 experimental trials in each block: 50 word-word trials ( 25 related, 25 unrelated) and 50 word-nonword trials.

Procedure. The participants were tested in groups of 4-8 in a quiet room. Presentation of the stimuli and recording of RTs were controlled by Apple Macintosh Performa 6200 microcomputers. On each trial, a forward mask composed of a row of 11 hash-marks (\#\#\#\#\#\#\#\#\#\#) was presented for $500 \mathrm{msec}$ on the center of the screen. Next, a centered lowercase prime word was presented for $100 \mathrm{msec}$. Primes were immediately replaced by an uppercase target item. The target word (or nonword) remained on the computer screen until the participant responded or until $2 \mathrm{sec}$ had elapsed. RTs were measured from target onset until the participant's response. In the go/no-go block, the participants were instructed to press a button on the keyboard with their dominant hand if the uppercase letter string was a legitimate Spanish word. In the yes/no block, the participants were instructed to press one of two buttons on the keyboard to indicate whether the uppercase letter string was a Spanish word or not. The participants used their dominant hand to make the word response. In both tasks, this decision was to be made as rapidly and as accurately as possible. The intertrial interval was set to $400 \mathrm{msec}$. Each participant received a total of 20 practice trials prior to each experimental block. There was a short break between the first and the second block. Stimulus presentation was randomized, with a different order for each participant. The session lasted approximately $18 \mathrm{~min}$.

\section{Results}

Incorrect responses (3.2\%) and RTs less than $250 \mathrm{msec}$ or greater than $1,500 \mathrm{msec}(0.24 \%$ of the data) were excluded from the latency analysis. Mean lexical latencies for correct responses and error rates were calculated across individuals and across items. Separate ANOVAs were performed for Block 1 and Block 2. Participant and item ANOVAs based on the participants' and items' response latencies and percentage error in each block were conducted on the basis of a 2 (associative relatedness, related or unrelated) $\times 2$ (task, go/no-go or yes $/$ no $) \times 2$ (set, Set A or Set B) $\times 2$ (list, List 1 or List 2 ) design. The set and list factors were included as dummy variables to extract the variance owing to the error associated with the

Table 3

Mean Response Times (RTs, in Milliseconds) and Percentages of Errors on Target Words in Experiment 2

\begin{tabular}{|c|c|c|c|c|}
\hline Condition & \multicolumn{2}{|c|}{ Block 1} & \multicolumn{2}{|c|}{ Block 2} \\
\hline & \multicolumn{2}{|c|}{ Go/No-Go Task } & \multicolumn{2}{|c|}{ Yes/No Task } \\
\hline Go-Yes/No Group & $M$ & PE & $M$ & $\mathrm{PE}$ \\
\hline Related & 547 & 0.4 & 604 & 6.6 \\
\hline Unrelated & 571 & 0.4 & 621 & 7.0 \\
\hline \multirow[t]{2}{*}{ Priming effect } & 24 & 0.0 & 17 & 0.4 \\
\hline & \multicolumn{2}{|c|}{ Yes/No Task } & \multicolumn{2}{|c|}{ Go/No-Go Task } \\
\hline \multirow{3}{*}{$\begin{array}{l}\text { Yes/No-Go Group } \\
\text { Related } \\
\text { Unrelated }\end{array}$} & $M$ & $\mathrm{PE}$ & $M$ & $\mathrm{PE}$ \\
\hline & 613 & 5.3 & 556 & 0.4 \\
\hline & 623 & 5.3 & 575 & 0.4 \\
\hline Priming effect & 10 & 0.0 & 19 & 0.0 \\
\hline
\end{tabular}

Note-Priming effect refers to the difference between the unrelated condition and the related condition. Percentages of errors for nonwords were $6.5 \%$ and $6.1 \%$ for the go/no-go lexical decision task (LDT) and the yes/no LDT, respectively. 
lists (see Pollatsek \& Well, 1995). The mean RTs and percentage error from the participant analysis are presented in Table 3.

Block 1. The ANOVA on the latency data showed that the main effect of associative relatedness was significant $\left[F_{1}(1,48)=15.31, M S_{\mathrm{e}}=548.6 ; F_{2}(1,96)=11.72, M S_{\mathrm{e}}=\right.$ $2,654.7]$, in which targets preceded by related primes were responded to faster than when preceded by unrelated primes. The main effect of task was also significant $\left[F_{1}(1,48)=11.65, M S_{\mathrm{e}}=8,528.8 ; F_{2}(1,96)=318.87, M S_{\mathrm{e}}=\right.$ 1,179.2]: The participants in the go/no-go task had faster RTs than did those in the yes/no task. The interaction between the two factors was not significant $\left[F_{1}(1,48)=2.54\right.$, $M S_{\mathrm{e}}=548.5, p>.10 ; F_{2}(1,96)=2.70, M S_{\mathrm{e}}=1,803.0, p>$ .10].

The ANOVA on the error data showed only that the main effect of task was significant $\left[F_{1}(1,48)=30.82, M S_{\mathrm{e}}=\right.$ $\left.28.81 ; F_{2}(1,96)=30.96, M S_{\mathrm{e}}=73.99\right]$ : The participants in the yes/no task made more errors than did those in the go/nogo task.

Block 2. The ANOVA on the latency data showed that the main effect of associative relatedness was significant $\left[F_{1}(1,48)=20.06, M S_{\mathrm{e}}=413.7 ; F_{2}(1,96)=8.55, M S_{\mathrm{e}}=\right.$ 4,493.7]: Targets preceded by related primes were responded to faster than those preceded by unrelated primes. The main effect of task was also significant $\left[F_{1}(1,48)=\right.$ $\left.7.49, M S_{\mathrm{e}}=8,365.0 ; F_{2}(1,96)=114.1, M S_{\mathrm{e}}=2,100.7\right]$ : The participants in the go/no-go task had faster RTs than did those in the yes/no task. The interaction between these two factors did not approach significance (both $F_{\mathrm{S}}<1$ ).

The ANOVA on the error data showed only that the main effect of task was significant $\left[F_{1}(1,48)=87.17\right.$, $\left.M S_{\mathrm{e}}=13.57 ; F_{2}(1,96)=100.6, M S_{\mathrm{e}}=41.0\right]$ : The participants in the yes/no task made more errors than did those in the go/no-go task.

Finally, we should note that if we analyze separately the two tasks, the error variance for the relatedness effect, in terms of $M S_{\mathrm{e}} \mathrm{s}$, did not differ significantly between the two tasks. Specifically, the $M S_{\mathrm{e}}$ s were 560.5 versus $536.6\left(F_{1}\right.$, first block), 415.0 versus 412.3 ( $F_{1}$, second block), $2,061.5$ versus 2,396.5 ( $F_{2}$, first block), and 3,917.7 versus $2,971.0$ $\left(F_{2}\right.$, second block), in the go/no-go and the yes/no task, respectively.

\section{Discussion}

The results of this experiment are straightforward. First, the participants were faster and more accurate when performing the go/no-go task than when performing the yes/no task, replicating the data from Experiment 1. Interestingly, we found the advantage of the go/no-go task not only with a between-subjects manipulation (as in Experiment 1), but also with a within-subjects manipulation: The participants who had performed the yes/no task in the first block had much faster latencies (and fewer errors) when they performed the go/no-go task in the second block [618 vs. $565.5 \mathrm{msec}$, respectively; $F_{1}(1,24)=32.79, M S_{\mathrm{e}}=2,389.0$; $F_{2}(1,96)=114.1, M S_{\mathrm{e}}=2,100.7$; the error rates were $5.3 \%$ vs. $0.4 \%$, respectively]. Conversely, the participants who had performed the go/no-go task in the first block had much longer latencies (and more errors) when they performed the yes/no task in the second block [559 vs. $612.5 \mathrm{msec}$, respectively; $F_{1}(1,24)=25.95, M S_{\mathrm{e}}=3,645.9$; $F_{2}(1,96)=318.9, M S_{\mathrm{e}}=1,179.2$; the error rates were $0.4 \%$ vs. $6.8 \%$, respectively]. Taken together, these results confirm the fact that the participants' responses are faster and more accurate in the go/no-go task. Second, the go/no-go task is clearly sensitive to the influence of automatic associative priming. In fact, the priming effect was (if anything) a bit greater for the go/no-go task $(21.5 \mathrm{msec})$ than for the yes/no task $(13.5 \mathrm{msec})$, although the interaction did not approach significance in a combined analysis with the two blocks.

It is important to note that the number of false positives (nonword error rates) was a bit higher in the go/no-go task than in the yes/no task (6.5\% vs. $6.1 \%)$, but this difference was nowhere near significance $(F<1)$. Finally, as in Experiment 1 , the error variance in the go/no-go task was not consistently lower than that in the yes/no task.

\section{GENERAL DISCUSSION}

The present study has provided evidence that the go/nogo LDT is sensitive to the effects of word frequency and associative priming: The magnitude of these effects was similar to that found with the standard yes/no LDT. More important, the go/no-go task appears to enjoy a number of advantages over the yes/no task (in three out of the four criteria discussed in the introduction): It offers faster RTs, more accurate responding, and fewer processing demands than the yes/no task. However, contrary to Gordon's (1983) claim, the variability in the data, as measured by the $M S_{\mathrm{e}}$, does not seem to be smaller in the go/no-go task.

\section{Speed of Response and Accuracy in the Go/No-Go Task}

RTs seem to be substantially faster with the go/no-go task than with the yes/no task (for both high- and lowfrequency words), both across participants (Experiments 1-2) and within participants (Experiment 2). More important, this reduction in RTs in the go/no-go task was accompanied by a dramatic decrease in the word error rate (while keeping a similar rate of nonword errors), which implies that there is an error component in the yes/no task that is minimized in the go/no-go task. It seems that the standard yes/no task may require some time-consuming decisional processes that are unnecessary to make a correct word response.

It is of obvious interest to analyze why participants commit errors to word stimuli under unlimited viewing conditions in a lexical decision task. Perhaps the most cited and detailed framework for understanding the yes/no lexical decision task is the one proposed by Balota and Chumbley $(1984,1990 ;$ see also Balota \& Spieler, 1999). Although Balota and Chumbley apply their model primarily to RT data, they also analyze the causes of word errors. Specifically, within the Balota and Chumbley model, errors to 
word stimuli in the yes/no task can derive from multiple sources (see Balota \& Chumbley, 1984; Balota \& Spieler, 1999), as follows.

1. Errors could occur because of misperceptions in early perceptual analyses.

2. Errors could occur in terms of a fast guess when a word has an extremely low familiarity value (e.g., when the word has an unusual spelling: lilac, yacht).

3. Errors could occur in the lexical selection stage when the participant has established a time criterion for a positive/negative response, after which a guess will be made because he or she is still unsure about whether the letter string is spelled correctly or not (see Forster \& Veres, 1998; Lesch \& Pollatsek, 1998).

4. Errors could occur in the lexical selection stage when there is a lack of knowledge about the appropriate spelling of a word.

5. Errors could occur on the basis of momentarily forgetting which keys correspond to word and nonword.

In contrast, in the go/no-go task, errors to word stimuli will be caused primarily because of a lack of knowledge about the appropriate spelling of a word (keep in mind that, unlike the yes/no task, there is no emphasis on generating a fast response to the all stimuli). It is worth noting that the percentage of errors for low-frequency words in Experiment 1 is negligible in the go/no-go task $(0.4 \%$; it was $0.0 \%$ for high-frequency words), much smaller than that for high-frequency words in the yes/no task $(1.7 \%)$. The $1.7 \%$ error rate for high-frequency words in the yes/no task is probably due to some early perceptual errors or because the participant executed the wrong response (once the letter string was correctly classified as a word). (Of course, it is possible that a very small percentage of errors to word stimuli could also be caused by the participants' inattention.)

The presence of a 3\%-6\% false positive errors (relative to a negligible word error rate) in the go/no-go task might suggest that there is a substantial word bias in this task that does not exist in the yes/no task (i.e., word and nonword error rates are about equal in the yes/no task, around $3 \%-6 \%)$. However, as we stated earlier, well-motivated participants should not make an error to a word item in a go/no-go LDT unless they do not know for sure the spelling of a given word; after all, they have $2 \mathrm{sec}$ to identify the word. As for the presence of occasional nonword errors in the go/no-go task - a rate that was similar to that obtained with the yes/no task-we believe that these errors are inherent whenever there is pressure for rapid responding (see Luce, 1986). As Pachella (1974) has pointed out, if a participant never makes a false positive (i.e., a nonword error), he or she will never know if he or she could be a little faster still without making errors. In any event, this is an aspect of the experiment that is, to some degree, outside the direct control of the researcher.

\section{What is the Locus of the Go/No-Go Advantage?}

In the introduction, we assumed a discrete stage model of performance in which the subprocesses were identified as successive temporal stages (i.e., lexical selection, response decision, and response selection). This assumption of successive processing seems compelling, since the processes are logically contingent upon each other. ${ }^{10} \mathrm{We}$ also assumed that the basic difference between making a word response in the two techniques (go/no-go and yes/no LDT) seems to be the mental operations involved in the response selection stage. The response selection stage was posited to be independent of factors such as word frequency, since the decision has already been taken in the response decision process. As a result, it was predicted that task and word frequency should show additive effects, as actually occurred in Experiment 1. However, the data from Hino and Lupker $(1998,2000)$ strongly suggest that word frequency could also affect differentially decisional processing in the yes/no and the go/no-go tasks; if not, the higher word error rates in the yes/no task would be left unexplained. Moreover, the long RTs in the yes/no task after a block with the go/no-go task (Experiment 2) - but not the other way around-suggest that the difference in the two tasks could also rely on the response decision process (or even earlier), and not just on the response selection process.

An important source of difference between the yes/no LDT and the go/no-go LDT can be the presence of response competition in the yes/no task (see Grice \& Reed, 1992, for evidence of response competition in a two-letter classification experiment with the two procedures). In this way, it could be argued that a factor such as word frequency has an effect at a response conflict locus in the yes/no LDT, which would delay the response to the target item, since low-frequency words may produce evidence favoring the word and the nonword responses simultaneously (see Abrams \& Balota, 1991). In contrast, responseconflict is probably absent —or at least minimized —in the go/no-go task, since nonwords do not require an overt response. ${ }^{11}$ Apparently, there is a problem with this account: It may actually predict a larger word frequency effect in the yes/no task than in the go/no-go task. But appearances may be deceiving. This larger word frequency effect in the yes/no task would occur if the error rates were equivalent in the two tasks (see the Discussion section of Experiment 1). However, in the usual experimental setup, participants make substantially more word errors-especially for the low-frequency words - in the yes/no LDT than in the go/no-go LDT. These trials in the yes/no task would end up counting as errors and not contributing to the mean latency for low-frequency words. In contrast, in the go/nogo LDT, nonwords do not require a response, and the participant could eventually realize that the unfamiliar item is a word, producing a slow response (Hino \& Lupker, 1998). In other words, the relatively high error rates for the lowfrequency words in the yes/no task may have introduced "potential distortion of the observed mean reaction time from the mean reaction time that would be observed had errors not removed trials that might otherwise have produced long reaction times" (McClelland, 1979, p. 319). If the previous reasoning is correct, the task $\times$ word fre- 
quency interaction could show not only a larger word frequency effect in the yes/no task (assuming a similar rate of errors in the two tasks), but also additive effects (as in Experiment 1; see also Gordon \& Caramazza, 1982; Perea et al., 1998) or even a larger word frequency effect in the go/no-go task (as in Hino \& Lupker, 1998, 2000). As Luce (1986) pointed out, Sternberg's (1969) additive-factor method focuses exclusively on RTs (i.e., assuming errorfree performance), and it is not simple to generalize this method to the analysis of error data.

One alternative explanation of the present results is in terms of the random-walk framework proposed by Stone and Van Orden (1993; see also Gordon, 1983; Ratcliff, 1978; Ratcliff, Gómez, \& McKoon, 2001) for the yes/no LDT. From a modeler's perspective (e.g., Smith, 2000), ${ }^{12}$ the yes/no task has two absorbing barriers (i.e., a word response would be emitted when the accumulated activation of evidence reaches a given positive criterion $a_{1}$, whereas a nonword response would be emitted when the accumulated activation falls below a given negative criterion $a_{2}$ ), whereas the go/no-go task has only one absorbing barrier (i.e., a word response would be emitted when the accumulated activation exceeds a given positive criterion $a$ ). There are several basic parameters of a random-walk process when applied to a yes/no LDT (Stone \& Van Orden, 1993): (1) the criterion level of evidence for a word response, (2) the criterion level of evidence for a nonword response, and (3) the parameters responsible for the rate of word (and nonword) accumulation. In a go/no-go LDT, the criterion for nonword responses (or the parameters for nonword accumulation) would be superfluous. Interestingly, the Stone and Van Orden model can be used for precise (albeit qualitative) predictions concerning responses to both word and nonword stimuli. At first glance, the fact that participants make faster word responses in the go/nogo task than in the yes/no task suggests that participants might use a lower criterion for word responses in the go/nogo task. However, moving the word criterion toward origin would also increase the probability of a false positive (i.e., the nonword error rate; see Stone \& Van Orden, 1993). In the present experiments, the faster responding in the go/no-go task than in the yes/no task was also accompanied by a similar nonword error rate in the two techniques, which seems to rule out this option. Instead, what would happen if the participants speed the word accumulation process in the simpler task (i.e., the go/no-go task, since it may require less cognitive load)? The effect of speeding the word accumulation rate would be a decrease in the RTs and in the word error rate, relative to the more complex yes/no task, as actually occurred. More important, speeding the word accumulation rate does not modify the probability of a false positive (see Stone \& Van Orden, 1993, Table 6). Interestingly, recent research suggests that participants can strategically increase/decrease the word accumulation rate (or the so-called input gain in connectionist models) in the process of word reading (see Kello \& Plaut, 2000). What are the predictions of the Stone and Van
Orden model with respect to the additivity/interaction between word frequency and task? Unfortunately, as we said earlier, the Stone and Van Orden model does not make quantitative predictions, although it is likely that the net effect could depend on such factors as the accuracy of the responses.

\section{Task Demands and Variability in the Go/No-Go Task}

The fact that participants have longer latencies in the yes/no task after a block with the go/no-go task, whereas participants have much shorter latencies in the go/no-go task after a block with the yes/no task (see Experiment 2), suggests that the go/no-go task makes fewer task demands; after all, the participants were using the same key for word responses in the two blocks. Of course, this can also be viewed as simply a restatement that the go/no-go task produces faster RTs and fewer errors than does the yes/no task. More direct evidence on this issue would probably be obtained with a dual-task experiment. In any event, it is important to note that the go/no-go LDT, but not the yes/no LDT, can be easily applied to experiments with children or special populations (Yelland, 1993).

However, there is one important property in which there is not such an advantage of the go/no-go task relative to the yes/no task: the variability (noise) in the data. If we use error variance, as measured by $M S_{\mathrm{e}} \mathrm{s}$, as an estimate of the sensitivity of the procedure, the variability tends to be somehow higher with the go/no-go task than with the yes/no task (see also Hino \& Lupker, 1998, 2000), although the pattern is not entirely consistent. In any case, these results show that the claim that the go/no-go LDT produces data that are less noisy than those in the yes/no task (Gordon, $1983,1985)$ is probably wrong. ${ }^{13}$ One reason why the go/no-go task might not produce less error variance than the yes/no task is probably related to the fact that some of the variability corresponding to the word stimuli is removed by the false negative errors in the yes/no technique. In other words, what would be the (true) error variance if participants were as accurate in the yes/no task as they are in the go/no-go task? Bear in mind that errors in early perceptual analysis would correspond to a false negative response in the yes/no task, whereas they would correspond to a relatively long latency in the go/no-go task (Hino \& Lupker, 1998), thereby increasing variability in the data. Undoubtedly, the fact that errors take out trials that would otherwise contribute to mean RTs is troublesome (McClelland 1979). Thus, the (possible) reduction in error variance in the yes/no LDT (relative to the go/no-go task) might just reflect an artifact of the task.

\section{Implications for Future Research}

The message we want to convey is that the go/no-go LDT seems to be a simple, promising task - at least for devotees of the LDT - that offers more accurate responding, faster RTs, and fewer processing resources than does the yes/no task. It may also provide "more time for word dynamics to 
run toward coherent states" (Gibbs \& Van Orden, 1998, p. 1180). Accordingly, unless one intends to examine the RT for nonwords, the go/no-go task appears to be an excellent alternative to the standard yes/no task. Furthermore, as McClelland (1979) pointed out, firm conclusions about the locus of the effect of a manipulation must be restricted to cases in which error rates are very low, as seems to be the case with the go/no-go LDT. In fact, more attention should be devoted to the analysis of word/nonword errors in the yes/no LDT, since it might compromise the pattern of results in the RT analysis for a given effect (see Luce, 1986). Undoubtedly, as Grainger and Jacobs (1996; Grainger, Carreiras, \& Perea, 2000) have pointed out, theoretical progress to study word recognition is highly dependent on the study of cross-task comparisons. Time will tell whether the go/no-go procedure applied to the lexical decision task is as fruitful as it seems.

\section{REFERENCES}

Abrams, R. A., \& Balota, D. A. (1991). Mental chronometry: Beyond reaction time. Psychological Science, 2, 153-157.

Alameda, J. R., \& Cuetos, F. (1995). Diccionario de frecuencia de las unidades lingüísticas del castellano [Dictionary of word frequency in Spanish]. Oviedo: Servicio de publicaciones de la Universidad de Oviedo.

Algarabel, S., Sanmartín, J., García, J., \& Espert, R. (1986). Normas de asociación libre de 400 sustantivos pertenecientes a BASPAL [Norms of free association for 400 nouns in the BASPAL database]. Informes del Departamento de Psicología Experimental, Universitat de València, Spain.

Balota, D. A., \& Chumbley, J. I. (1984). Are lexical decisions a good measure of lexical access? The role of word frequency in the neglected decision stage. Journal of Experimental Psychology: Human Perception \& Performance, 10, 340-357.

Balota, D. A., \& Chumbley, J. I. (1990). Where are the effects of frequency in visual word recognition tasks? Right where we said they were! Comment on Monsell, Doyle, and Haggard (1989). Journal of Experimental Psychology: General, 119, 231-237.

Balota, D. A., \& Spieler, D. H. (1999). Word frequency, repetition, and lexicality effects in word recognition. Journal of Experimental Psychology: General, 128, 32-55.

Chiarello, C., Nuding, S., \& Pollock, A. (1988). Lexical decision and naming asymmetries: Influence of response selection and response bias. Brain \& Language, 34, 302-314.

Collins, A. M., \& Loftus, E. F. A. (1975). A spreading-activation theory of semantic processing. Psychological Review, 82, 407-428.

Davis, C., CAst les, A., \& IAKovidis, E. (1998). Masked homophone and pseudohomophone priming in children and adults. Language \& Cognitive Processes, 13, 625-651.

DE Groot, A. M. B. (1984). Primed lexical decisions: Combined effects of the proportion of related prime-target pairs and the stimulus-onset asynchrony of prime and target. Quarterly Journal of Experimental Psychology, 36A, 253-280.

den Heyer, K., Sullivan, A., \& McPherson, C. (1987). Mediated priming in a single-response lexical decision task. Unpublished manuscript.

DonDERS, F. C. (1969). Over de snelheid van psychische processen [On the speed of psychological processes]. Acta Psychologica, 30, 412431. (Original work published 1868)

Forster, K. I. (1976). Accessing the mental lexicon. In R. J. Wales \& E. W. Walker (Eds.), New approaches to languagemechanisms (pp. $257-$ 287). Amsterdam: North-Holland.

Forster, K. I., \& SHEN, D. (1996). No enemies in the neighborhood: Absence of inhibitory effects in lexical decision and categorization. Journal of Experimental Psychology: Learning, Memory, \& Cognition, 22, 696-713.
Forster, K. I., \& Veres, C. (1998). The prime lexicality effect: Formpriming as a function of prime awareness, lexical status, and discrimination difficulty. Journal of Experimental Psychology: Learning, Memory, \& Cognition, 24, 498-514.

GibBs, P., \& Van Orden, G. C. (1998). Pathway selection's utility for control of word recognition. Journal of Experimental Psychology: Human Perception \& Performance, 24, 1162-1187.

Gordon, B. (1983). Lexical access and lexical decision: Mechanisms of frequency sensitivity. Journal of Verbal Learning \& Verbal Behavior, 22, 24-44.

Gordon, B. (1985). Subjective frequency and the lexical decision latency function: Implications for mechanisms of lexical access. Journal of Memory \& Language, 24, 631-645.

Gordon, B., \& Caramazza, A. (1982). Lexical decision for open- and closed-class words: Failure to replicate differential frequency sensitivity. Brain \& Language, 15, 143-160.

Grainger,J., Carreiras, M., \& Perea, M. (2000). A new technique for visual word recognition research: The luminance increment paradigm. Current Psychology Letters, 1, 107-116.

Grainger, J., \& JACOBS, A. M. (1996). Orthographic processing in visual word recognition: A multiple read-out model. Psychological Review, 103, 518-565.

Grainger, J., O’Regan, J. K., Jacobs, A. M., \& Seguí, J. (1989). On the role of competing word units in visual word recognition: The neighborhood frequency effect. Perception \& Psychophysics, 45, 189-195.

Grice, G. R., \& ReED, J. M. (1992). What makes targets redundant? Perception \& Psychophysics, 51, 437-442.

HINO, Y., \& LUPKER, S. J. (1996). Effects of polysemy in lexical decision and naming: An alternative to lexical access accounts. Journal of Experimental Psychology: Human Perception \& Performance, 22, 1331-1356.

Hino, Y., \& LupKer, S. J. (1998). The effects of word frequency for Japanese Kana and Kanji words in naming and lexical decision: Can the dual-route model save the lexical-selection account? Journal of Experimental Psychology: Human Perception \& Performance, 24, 1431-1453.

Hino, Y., \& LuPKER, S. J. (2000). The effects of word frequency and spelling-to-sound regularity in naming with and without lexical decision. Journal of Experimental Psychology: Human Perception \& Performance, 26, 166-183.

Kello, C. T., \& Plaut, D. C. (2000). Strategic control in word naming: Evidence from speeded responding in the tempo naming task. Journal of Experimental Psychology: Learning, Memory, \& Cognition, 26, 719-750.

LAne, D. M., \& Ashby, B. (1987). PsychLib: A library of machine language routines for controlling psychology experiments on the Apple Macintosh computer. Behavior Research Methods, Instruments, \& Computers, 19, 246-248.

Lesch, M. F., \& Pollatsek, A. (1998). Evidence for the use of assembled phonology in accessing the meaning of printed words. Journal of Experimental Psychology: Learning, Memory, \& Cognition, 24, 573-592.

LuCE, R. D. (1986). Response times. New York: Oxford University Press.

McClelland, J. L. (1979). On the time relations of mental processes: An examination of systems of processes in cascade. Psychological Review, 86, 287-330.

McClelland, J. L., \& Rumelhart, D. E. (1981). An interactive activation model of context effects in letter perception: 1 . An account of basic findings. Psychological Review, 88, 375-407.

McNamara, T. P., \& Altarriba, J. (1988). Depth of spreading activation revisited: Semantic mediated priming occurs in lexical decisions. Journal of Memory \& Language, 27, 545-559.

MeAsso, G., \& ZAIDEL, E. (1990). Effect of response programming on hemispheric differences in lexical decision. Neuropsychologia, 28, 635-646.

Monsell, S., Doyle, M. C., \& Haggard, P. N. (1989). Effects of frequency on visual word recognition tasks: Where are they? Journal of Experimental Psychology: General, 118, 43-71.

Neely, J. H. (1991). Semantic priming effects in visual word recognition: A selective review of current findings and theories. In D. Besner and G. W. Humphreys (Eds.), Basic processes in reading: Visual word recognition (pp. 264-336). Hillsdale, NJ: Erlbaum. 
PaAp, K. R., McDonald, J. E., Schvaneveldt, R. W., \& Noel, R. W. (1987). Frequency and pronounceability in visually presented naming and lexical decision tasks. In M. Coltheart (Ed.), Attention and Performance XII: The psychology of reading (pp. 221-243). Hove, U.K.: Erlbaum.

PaAp, K. R., Newsome, S. L., McDonald, J. E., \& Schvaneveldt, R. W. (1982). An activation-verification model for letter and word recognition: The word superiority effect. Psychological Review, 89, 573-594.

PACHElla, R. G. (1974). The interpretation of reaction time in information processing research. In B. Kantowitz (Ed.), Human information processing: Tutorials in performance and cognition (pp. 41-81). Potomac, MD: Erlbaum.

Perea, M., Fernández, L., \& Carreiras, M. (1998, December). Efectos secuenciales en la tarea de decisión léxica [Sequential effects in the lexical decision task]. Paper presented at the II Conference of the Spanish Experimental Psychology Society, Granada, Spain.

Perea, M., \& Pollatsek, A. (1998). The effects of neighborhood frequency in reading and lexical decision. Journal of Experimental Psychology: Human Perception \& Performance, 24, 767-779.

Pollatsek, A. Perea, M., \& Binder, K. (1999). The effects of "neighborhood size" in reading and lexical decision. Journal of Experimental Psychology: Human Perception \& Performance, 25, 1142-1158.

Pollatsek, A., \& Well, A. (1995). On the use of counterbalanced designs in cognitive research: A suggestion for a better and more powerful analysis. Journal of Experimental Psychology: Learning, Memory, \& Cognition, 21, 785-794.

RatCliff, R. (1978). A theory of memory retrieval. Psychological Review, 85, 59-108.

RATCLIFF, R. (1979). Group reaction time distributions and an analysis of distribution statistics. Psychological Bulletin, 86, 446-461.

Ratcliff, R, Gómez, P., \& McKoon, G. (2001).A diffusionmodel account of the lexical decision task. Manuscript submitted for publication.

Schilling, H. E. H., Rayner, K., \& Chumbley, J. I. (1998). Comparing naming, lexical decision, and eye fixation times: Word frequency effects and individual differences. Memory \& Cognition, 26, 1270-1281.

Smith, P. L. (2000). Stochastic dynamic models of response time and accuracy: A foundational primer. Journal of Mathematical Psychology, 44, 408-463.

STERnBERG, S. (1969). The discovery of processing stages: Extensions of Donders' method. Acta Psychologica, 30, 276-315.

Stone, G. O., \& VAn Orden, G. C. (1993). Strategic control of processing in visual word recognition. Journal of Experimental Psychology: Human Perception \& Performance, 19, 744-774.

Ulrich, R., Mattes, S., \& Miller, J. (1999). Donders's assumption of pure insertion: An evaluation on the basis of response dynamics. Acta Psychologica, 102, 43-75.

Westall, R., Perkey, M. N., \& Chute, D. L. (1986). Accurate millisecond timing on Apple's Macintosh using Drexler's MilliTimer. Behavior Research Methods, Instruments, \& Computers, 18, 307-311.

Yelland, G. (1993, November). Is there a place for phonological processes in reading development? Paper presented at the 9th Australian Language and Speech Conference, Sydney, Australia.

\section{NOTES}

1. We thank an anonymous reviewer for suggesting this scheme.

2. However, Chiarello, Nuding, and Pollock (1988) and Measso and Zaidel (1990) did not find a reliable effect of task in the error data when the stimuli were presented very briefly ( $100 \mathrm{msec}$ in the Chiarello et al. experiment and $80 \mathrm{msec}$ in the Measso \& Zaidel experiment) in the left/right visual field.
3. The first step is to compute the quantiles for each participant and condition. In our study, we used 5\% quantiles (i.e., 19 quantiles for each participant and condition). Second, each quantile is averaged across participants to give group quantiles. Third, group distribution histograms (Vincent histograms) can be easily constructed by plotting quantiles on the abscissa and then constructing rectangles between adjacent quantiles so that all the rectangles have equal areas (each rectangle has an area of $1 / q$, where $q$ is the number of quantiles). Interestingly, Vincent histograms produce average distributions with the same shape as component distributions (see Ratcliff, 1979).

4. Although these words are not very unfamiliar, perhaps the fact that billón has a similarly spelled word of much higher frequency (millón, the Spanish for million; see, e.g., Perea \& Pollatsek, 1998) and that $d e$ hesa has an unusual syllabic structure (i.e., in Spanish it is very unusual to find a mute " $h$ " in the middle of a word), combined with the time pressure of the LDT, caused participants to frequently consider them as nonwords.

5. We should note that the Hino and Lupker experiments were carried out in different languages (i.e., Japanese in the 1998 report and English in the 2000 report) than was the present experiment (i.e., Spanish). Perhaps this fact might have created some differences between experiments (especially the experiments in Japanese with respect to the experiments with alphabetical languages), although we cannot see how this difference can account for the seemingly contradictory results.

6. We thank Yasushi Hino for this suggestion.

7. We thank Ken Paap for this sharp observation.

8. We should note that Neely (1991) cited an unpublished study of den Heyer, Sullivan, and McPherson (1987), in which they found mediated priming (e.g., lion-STRIPES; via tiger) with the go/no-go LDT, but not with the standard yes/no LDT.

9. We thank an anonymous reviewer for this suggestion.

10. Bear in mind that it is not simple to make predictions from a model in which the transfer of information between processes is taking place all the time (a cascade model; see, e.g., McClelland, 1979), since it assumes very low error rates, which is not usually the case with low-frequency words in the yes/no task. Furthermore, as Ulrich, Mattes, and Miller (1999) pointed out, the serial processing assumption may also accommodate top-down processes, as well as bottom-up processes.

11. As Yasushi Hino has suggested, an interference may also occur at the motor system, independent of any internal processing. In the yes/no task, participants are required to press one of two keys, and thereby two distinct motors programs have to be executed, depending on the lexical status of the stimulus. In fact, it is quite usual for participants to say, after a yes/no lexical decision experiment, that they have made some mistakes because they automatically pressed a wrong key, especially after several word (or nonword) trials in a row.

12. We thank Gregory Ashby for this suggestion.

13. In order to examine whether the go/no-go task could produce less noisy data than the yes/no task, we also analyzed how the two tasks differed with respect to the within-cell standard deviation (averaged across participants). Note that the task differences might be more directly related to within-subjects (trial-by-trial) variability than the $M S_{\mathrm{e}} \mathrm{s}$. However, the statistical analyses on these variability data also failed to find any differences across tasks.

(Manuscript received January 23, 2001; revision accepted for publication October 29, 2001.) 